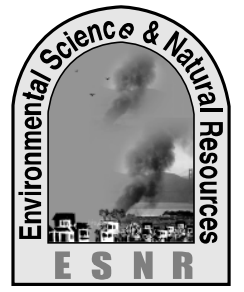

\title{
Water Supply and Sanitation Facilities in Primary School's of Gaibandha District in Bangladesh
}

\author{
M. S. Islam ${ }^{1}$, M. H. Rahaman ${ }^{1}$ and M. H. Sarker ${ }^{2}$ \\ ${ }^{1}$ Department of Environmental Science and Resource Management, \\ Mawlana Bhashani Science and Technology University, Tangail-1902, Bangladesh \\ ${ }^{2}$ Center for Environmental and Geographic Information Services (CEGIS), Dhaka, Bangladesh
}

\begin{abstract}
The purpose of this study is to monitor the present status of water supply and sanitation facilities of primary school in Gaibandha Sadar, Bangladesh. Forty nine (49) primary schools were selected for this purpose. The study revealed that, about $86 \%$ school had shallow tube well as a source for their drinking water supply and sanitation. About $18 \%$ schools had no sanitation facility or inactive sanitation unit. Separate toilet facility for girls and teachers was found in about 69 and 55\% schools respectively but only one school has separate toilet facility for male and female teacher. Availability of water, soap and hand washing facility inside girls and boys latrine is in average amount but in teachers toilet it was satisfactory. Most of the schools $(69 \%)$ have active drainage system at water point where $41 \%$ schools have basket in all classes for dumping of solid wastes. In this regard, the proper management and monitoring of existing facilities are required to improve the present water supply and sanitation situation in primary schools of Bangladesh.
\end{abstract}

Key words: Primary school, Sanitation facility, Students and teachers, Water supply

\section{Introduction}

The children's development, education and safety depend on them having access to clean water, knowledge about hygiene and a sanitary environment (UNICEF, 2012) In many countries there exists a high prevalence of water and sanitation related diseases, causing many people, children in particular, to fall ill or even die (UNICEF, 1998). Children who suffer constant water-related illness are at a disadvantage in school, as poor health directly reduces cognitive potential and indirectly undermines schooling through absenteeism, attention deficits and early dropout (UNDP, 2006). Additionally, the lack of adequate, segregated sanitation facilities for boys and girls at school discourages girls from attending full time, affecting their academic performance and perpetuating gender inequity.

Bangladesh faces many challenges related to water, sanitation, and hygiene because it is densely populated and prone to flooding. High levels of naturally-occurring arsenic pollute shallow groundwater, putting an estimated 35 million people at risk of chronic arsenic poisoning, which can cause cancer and affect cognitive development in children (Kinniburgh and Smedley, 2001). Frequent and recurring natural disasters, such as floods and cyclones, also trigger outbreaks of waterborne diseases, destroy existing sanitation facilities and compromise safe water supplies, compounding existing health issues (WHO, 2007).

Improved hygiene practices are essential if transmission routes of water and sanitation related diseases are to be cut. Whereas appropriate hygiene education can bring about the intention to change hygiene behavior, for most hygiene behaviors appropriate water and sanitation facilities are needed to allow people to transform intention to change into real change (UNICEF, 1998). There are approximately 78,000 primary schools in the country (almost every village has at least one primary school) and about 20 million students are enrolled. Currently, information on sanitation facilities in these schools is not available at national level. This may be an indication of the lack of attention on this crucial issue in the past (Nahar and Ahmed, 2006). Schools having only one latrine that exclusively used by the teachers only. Where there are two latrines, one is locked and reserved for use by the teachers and the other is used by both boys and girls. In such cases girls are often unwilling to use the latrines.

At present there are no readily available figures on the state of water supply and sanitation facilities in all primary schools in the country. An assessment of School Sanitation and Hygiene Education (SSHE) strategy with particular focusing on Technology design, the needs of adolescent girls and adequate water and sanitation facilities in schools was done by UNICEF (1998). The data collected from 4,388 primary schools, show the following key statistics: average of 246 students and 4 teachers per school, $19 \%$ schools have no water source, $28 \%$ have nonfunctional water source, $53 \%$ have functional water source, $6 \%$ have no latrine, $13 \%$ have a nonfunctional latrine, $25 \%$ have one latrine, $44 \%$ have two latrines, $12 \%$ have three or more latrines, $46 \%$ have separate latrines for girls, on average there is one latrine for 152 pupils (Nahar and Ahmed, 2006). 
The guideline figure on appropriate level of service in schools comes from the latest advice presented in a joint UNICEF-WSP document 'Toolkit on Hygiene Sanitation and Water in Schools'. To calculate ratio of number of latrines to number of students is based on several factors such as the types of breaks in the school timetable and whether urinals as well as latrines are to be used. However it is suggested that a ratio of average 25 students per toilet should be the basis of calculation. These figures illustrate the inadequacy of sanitary facilities in schools for children at school (Nahar and Ahmed, 2006). Considering the above views in mind, the present research work was undertaken with the objective to determine the present status of water supply and sanitation facilities in the primary school of Gaibandha District of Bangladesh.

\section{Materials and Methods}

\section{Sample size}

The present study is an attempt to examine the present status of water supply and sanitation facilities in the primary school of Bangladesh. Forty nine primary schools (38 Government and11 Non Government) were selected from Gaibandha Sadar, Bangladesh. Data was collected from those schools which have received financial and technical support for water supply and sanitation facilities.

\section{Data collection and analysis method}

A set of 20 close ended questionnaires was used to collect information related to water supply and sanitation condition of the primary school. Information was collected during the October to November, 2011. The statistical measures such as number and percent distribution were used for describing the variables of the study. The analysis was performed by using Microsoft Excel.

\section{Results and Discussions}

A total of 49 primary schools was selected for data collection related to water supply and sanitation. There are 38 government and 11 non government schools were found in the study area. General information about the primary school in the study area is presented in Table 1.

Table 1. General information about the surveyed primary schools of Gaibandha Sadar

\begin{tabular}{|c|c|c|c|c|}
\hline No. & Primary School & Status & No. of school & Percentage (\%) \\
\hline \multirow[t]{2}{*}{1} & \multirow[t]{2}{*}{ School type } & Government & 38 & 78 \\
\hline & & Non-government & 11 & 22 \\
\hline \multirow[t]{2}{*}{2} & \multirow[t]{2}{*}{ Student } & Boys & 7477 & 49 \\
\hline & & Girls & 7551 & 51 \\
\hline \multirow[t]{2}{*}{3} & \multirow[t]{2}{*}{ Physically disabled } & Boys & 34 & 59 \\
\hline & & Girls & 24 & 41 \\
\hline \multirow[t]{2}{*}{4} & \multirow[t]{2}{*}{ Teacher } & Male & 98 & 39 \\
\hline & & Female & 156 & 54 \\
\hline \multirow[t]{4}{*}{5} & \multirow[t]{4}{*}{ No. of classroom } & 3 & 21 & 43 \\
\hline & & 4 & 4 & 8 \\
\hline & & 5 & 10 & 20 \\
\hline & & $\geq 6$ & 14 & 29 \\
\hline \multirow[t]{4}{*}{6} & \multirow[t]{4}{*}{ Building type } & Pacca & 28 & 57 \\
\hline & & Semi-Pacca & 7 & 14 \\
\hline & & Pacca and Semi-Pacca & 12 & 25 \\
\hline & & Kacha & 4 & 4 \\
\hline 7 & Basket in all classes & Yes & 20 & 41 \\
\hline
\end{tabular}

\section{Water Supply}

Most of the schools use tube well for their water supply and sanitation purposes. About $86 \%$ of the total surveyed school use Tube Well No. 6 pump for water (Fig. 1). This is mainly because of low installation cost. Depth of water point was found between the ranges of $30 \mathrm{ft}$ to $210 \mathrm{ft}$ whereas depth was not found in 12 schools. Further depth has been classified into several classes in Fig. 2.
More than 120ft depth of water point was found in most schools of the study are who installed tube well recently. About $27 \%$ tube well was found $40-80 \mathrm{ft}$ because of low ground water table and old installation. About $96 \%$ water point was found to function where only $4 \%$ was found inactive. This is mainly because of improper maintenance. It has been found that about $90 \%$ water points have platform and $69 \%$ have active drainage system (Table 2 ). 


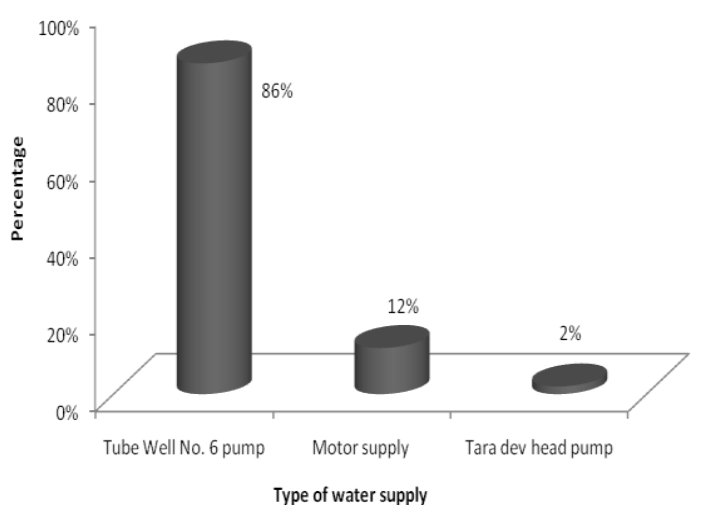

Fig. 1. Types of water supply in the study area

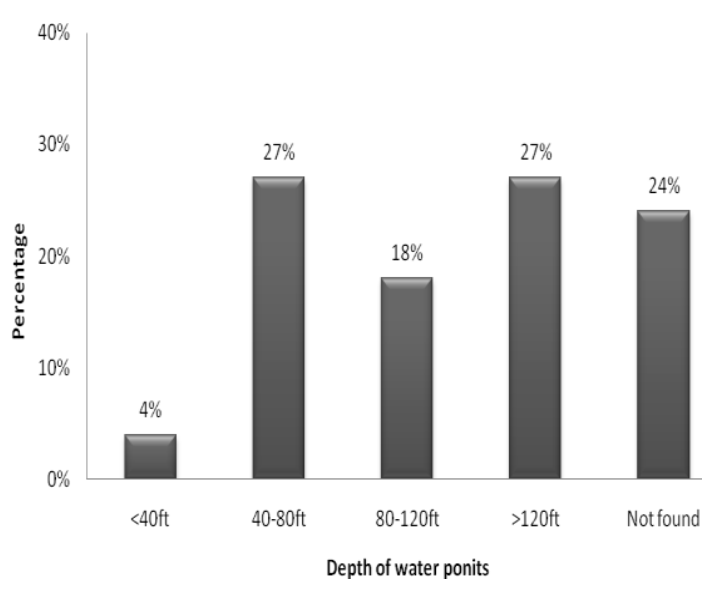

Fig. 2. Percent distribution of water point depth of the surveyed schools under different classes

Table 2. Information about water point

\begin{tabular}{|c|l|l|c|c|}
\hline No. & Water point & \multicolumn{1}{|c|}{ Condition } & No. of school & Percentage (\%) \\
\hline \multirow{2}{*}{1} & \multirow{2}{*}{ Status } & Functional & 47 & 96 \\
\cline { 3 - 5 } & & Non-functional & 2 & 4 \\
\hline 2 & \multirow{2}{*}{ Platform } & Yes & 44 & 90 \\
\cline { 3 - 5 } & & No & 5 & 10 \\
\hline \multirow{2}{*}{3} & \multirow{2}{*}{ Drainage System } & Functional & 34 & 69 \\
\cline { 3 - 5 } & & Non-functional & 15 & 31 \\
\hline \multirow{2}{*}{4} & \multirow{2}{*}{ Water logging } & Yes & 31 & 37 \\
\cline { 3 - 5 } & & No & & 63 \\
\hline
\end{tabular}

\section{Sanitation status}

In the study area it was found that about $82 \%$ schools had one or two functional toilet unit. In terms of toilet unit (function/non-functional) most of the school (23) has two or less (Fig. 3). Separate toilet facility for girls student was found in only $69 \%$ school whereas only $55 \%$ school was found separate toiler facility for teachers and separate toiler facility for male and female teacher was found in one school. Condition of soak pit was found functional in $90 \%$ school of the study area and $\mathrm{Y}$-junction was found function about $86 \%$ schools.

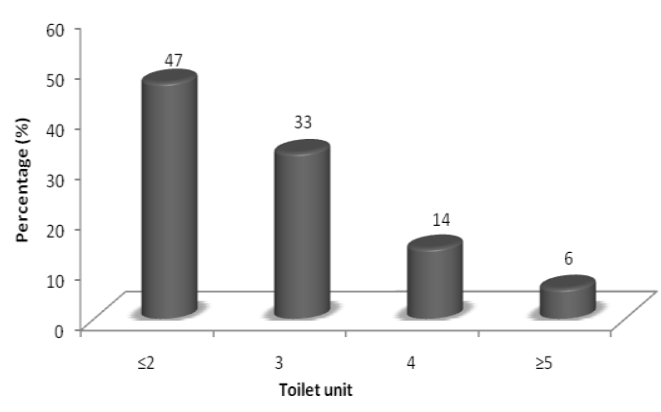

Fig. 3. Percent distribution of number of toilet unit in study area
From study it has found that about $63 \%$ school use bucket to carry water inside toilet where $31 \%$ use running water and $6 \%$ school have water facility inside the toilet (Fig. 4). No hand wash facility for students inside the toilet was found in the study area but $18 \%$ school have basin in toilet for teachers. About $20 \%$ schools have hand wash facility outside the toilet. Only $31 \%$ school was found soap inside the toilet of the total surveyed school. Distance between water point and toilet was found less than $10 \mathrm{~m}$ in most of the schools of the study area (Fig. 5).

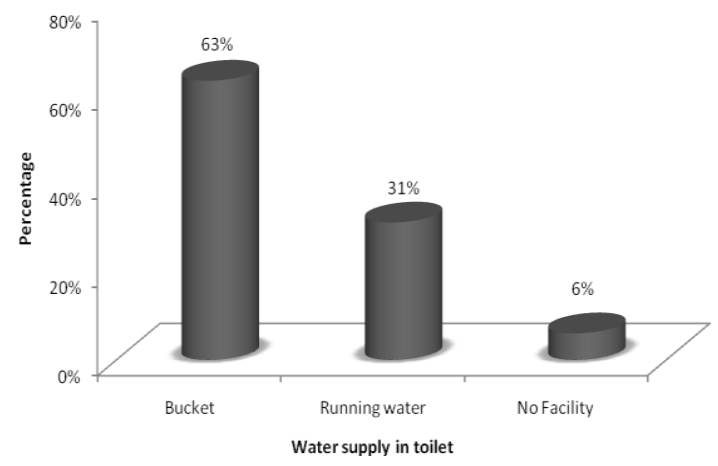

Fig. 4. Availability of water inside toilet 


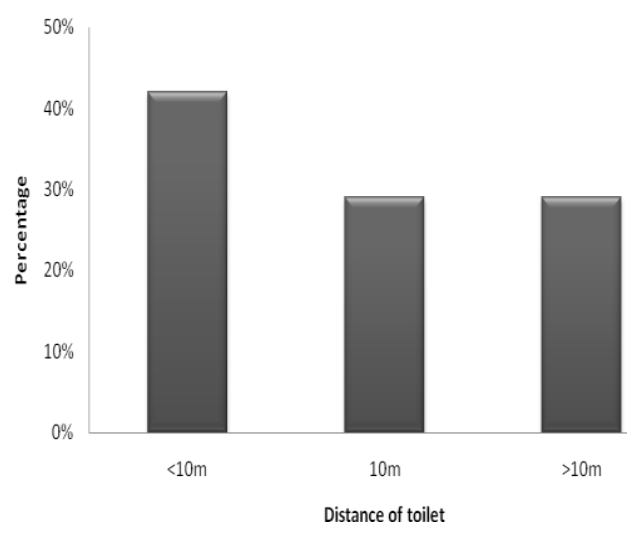

Fig. 5. Distance between water point and toilet in the study area

Several factors are involved that influence the present status of poor water supply and sanitation facilities. One of the major problems is the lack of proper maintenance of existing facilities. In practical it is difficult to maintain standard hygiene level while a large number of students attain the school and use tube wells and toilets. Training of students and make appropriate habit of use of such facilities could effectively solve the problem but unwillingness to repair the damage or broken part of water point or sanitation unit is a common tendency of most of the school management authority. Though sometimes it require big amount of financial budget but most of the cases need active management. Another major problem is lack of awareness among teachers, parents and their children who get to the school on effective use of water supply and sanitation facilities and their consecutive impacts on health and environment. Lack of financial budget and proper monitoring was notice during field study.

Study has been revealed that, about $86 \%$ school has shallow tube well for their water supply and sanitation. In case of sanitation, about $18 \%$ schools have no sanitation facility or inactive sanitation unit. Separate toilet facility for girls and teachers was found in about $69 \%$ and $55 \%$ schools respectively but only one school has separate toilet facility for male and female teacher was found in any school of Gaibandah Sadar. Availability of water, soap and hand washing facility inside girls and boys latrine is in average amount but in teachers toilet it was satisfactory. Most of the schools (69\%) have active drainage system at water point where $41 \%$ schools have basket in all classes for dumping of solid wastes. The following initiatives and monitoring can easily improve existing condition: i) effective management and monitoring of present status. These can be done through buildup student habit and encourage to proper use of tube wells and toilets guided by the teachers, ii) increase awareness among teachers, students and their parents related to water supply and sanitation, and iii) increase financial budget for these facilities and efficient management as well as monitoring.

\section{Acknowledgements}

Sincere thanks to them who helped with support, advice and ideas directly and indirectly to complete the research works successfully. Thanks also to Center for Environmental and Geographic Information Services (CEGIS) for helping and guiding us during the study period.

\section{References}

Kinniburgh, D. G. and Smedley, P. L. 2001. Arsenic Contamination of Groundwater in Bangladesh. Final Report (BGS Technical Report WC/00/19). Heyworth, UK: British Geological Survey.

Nahar, K. and Ahmed, R. 2006. Addressing special needs of girls Challenges in school. Presented in SACOSAN II, 2006 at Islamabad, Pakistan. pp. 3-4

UNICEF (United Nations Children's Emergency Fund), Bangladesh. 2012. Water, Environment and Sanitation. (Online) Available at: http://www.unicef.org/bangladesh/wes.html (Accessed 5 February 2012).

UNICEF (United Nations Children's Emergency Fund), IRC International Water and Sanitation Centre, 1998. A Manual on School Sanitation and Hygiene. (Online). Water, Environment and Sanitation Technical Guidelines SeriesNo.5.Available:http://www.unicef.org/wash/fil es/Sch_e.pdf (Accessed 5 February 2012).

UNDP (United Nations Development Programme). 2006. Human Development Report, Beyond Scarcity: Power, Poverty and the Global Water Crisis.(Online).Available:http://www.schoolsa ndhealth.org/Documents/BangladeshSuccesses and lessons learned from Nasirnaga Improving water and sanitation in schools and communities Brief2.pdf (Accessed 5 February 2012).

WHO (World Health Organization), Country Office for Bangladesh. 2007. Bangladesh Country Cooperation Strategy, 2008-2013. (Online). Available: Successes and lessons learned from Nasirnaga Improving water and sanitation in schools and communities Brief2.pdf (Accessed 5 February 2012). 